\title{
Development of Bioglass/PEEK Composite Coating by Cold Gas Spray for Orthopedic Implants
}

\author{
B. Garrido ${ }^{1}$ V. Albaladejo-Fuentes ${ }^{1}$ I. G. Cano ${ }^{1} \cdot$ S. Dosta $^{1}$
}

Submitted: 17 May 2021 / in revised form: 15 December 2021/Accepted: 16 December 2021/Published online: 10 January 2022 (C) ASM International 2022

\begin{abstract}
Cold gas spray (CGS) technology has allowed the development of biofunctional coatings composed of 45S5 and polyetheretherketone (PEEK). The combination of a bioactive glass material embedded in a polymeric matrix makes this composite an interesting material for orthopedic applications since this composite meets the biomechanical and biological requirements of an implant. In the present study, blends of bioactive glass $45 \mathrm{~S} 5$ and PEEK powder with different granulometry and 45S5/PEEK ratio have been prepared. These mixtures of powders have been deposited onto PEEK substrates by CGS with the goal of incorporating a bioactive additive to the biocompatible polymer, which can improve the bone-implant interaction of PEEK. The deposition efficiency (DE) of the coatings has been evaluated, and from the results obtained, it was possible to conclude that DE is significantly affected by the granulometry and by the 45S5/PEEK ratio of the blends. By scanning electron microscopy (SEM) inspection, it was observed that the use of blends with high 45S5/PEEK ratio lead to the deposition of coatings with high content of 45S5. Finally, the friction behavior of the coatings was
\end{abstract}

This article is an invited paper selected from presentations at the 2021 International Thermal Spray Conference, ITSC2021, that was held virtually May 25-28, 2021 due to travel restrictions related to the coronavirus (COVID-19) pandemic. It has been expanded from the original presentation.

\footnotetext{
B. Garrido

bgarrido@cptub.eu

S. Dosta

sdosta@ub.edu

1 Department of Materials Science and Physical Chemistry, University of Barcelona, Martí i Franquès, 1-1, 08028 Barcelona, Spain
}

analyzed performing ball-on-disk tests and these experiments showed that the presence of glass particles has a beneficial role in the wear resistance.

Keywords bioactive glass - biomaterials · cold spray · mixtures $\cdot$ PEEK $\cdot$ wear testing

\section{Introduction}

The replacement of damaged bone tissue with an implant is currently used widely to manage numerous diseases, with the implementation of this strategy increasing every year (Ref 1,2$)$. Its success is a consequence of the research performed over the years on new materials that meet the biomechanical and biological requirements of an artificial implant in order to reduce the number of rejections in patients (Ref 3,4). This field continues to evolve and some materials have already been consolidated for certain applications, such as stainless steel in temporary fixation devices and titanium in dental implants (Ref 5, 6). Currently, the improvement of implants to extend their durability and increase their success rate after implantation focuses on three different aspects: (i) the use of composite material, (ii) doping of conventional materials and (iii) surface modification. It should be noted though that the development and search of new biomaterials that have better properties than current ones are not being fully neglected.

Polyetheretherketone (PEEK) is a promising biomaterial for orthopedic applications. This biomaterial is a thermoplastic polymer in the polyaryletherketone (PAEK) family (Ref 7), which emerged in the late 1990s as an ideal candidate to replace metal implant components. PEEK is a biocompatible material that is chemically and physically 
stable and exhibits a similar elastic modulus to that of cortical bone, which makes it suitable for some orthopedic applications (Ref 8). However, PEEK is biologically inert and prevents good bonding when implanted in vivo. This drawback makes it fundamental to modify the biomaterial in order to improve its lack of bioactivity. For this purpose, surface modification (chemical treatment, physical treatment or surface coating) and composites with bioactive materials are the preferred strategies (Ref 9-18).

Bioactive glasses, discovered in 1969 at the University of Florida, are a group of reactive materials that can bond to bone tissue (Ref 19). These glasses are degradable in the body and stimulate bone cells to produce new bone, therefore being suitable for applications involving direct contact with the bone (Ref 20-23). 45S5 was the first bioactive glass to be developed and has the following composition: 45.0 $\mathrm{SiO}_{2}, 24.5 \mathrm{CaO}, 24.5 \mathrm{Na}_{2} \mathrm{O}$ and $6.0 \mathrm{P}_{2} \mathrm{O}_{5}$ (wt.\%). Due to its biological properties, this biomaterial is commercially available for specific clinical applications (Ref 23). However, their poor mechanical properties prevent these ceramic materials from being used in bulk and their application is restricted to the production of coatings, graft bone or scaffolds (Ref 20, 24-29).

Thus, a correct combination of PEEK and bioactive glasses may lead to the production of very promising PEEK composite biomaterials that combine the biocompatibility and bioactivity of both materials.

Cold gas spray (CGS) is a novel coating deposition technique that can be used at lower gas temperatures and high particle velocities (Ref 30, 31) when compared to conventional thermal spray technologies. During the deposition process, the substrate does not reach significantly high temperatures, which is very important when developing coatings on polymeric surfaces. In this specific technique, the particles deform and adhere to the substrate or to other particles and the coating is formed in a solidstate method (Ref 32, 33).

There are a few studies on the development of bioactive glass coatings by different thermal spray techniques in the literature (Ref 34-37); however, there is no study on the use of CGS in the deposition of bioactive glasses. The glass transition temperature of bioactive glasses makes it difficult to produce glass coatings using this technique. Taking into account the adhesion mechanism of the coatings in the CGS process, the combination of a polymer (PEEK) and glass (45S5) can help to deposit this new composite functional material. Sanpo et al. demonstrated, in 2009, the feasibility of deposit a ceramic material combined with PEEK polymer using CGS technology (Ref 38). In particular, they observed that the polymer formed a continuous matrix in which the silver ion-doped HA was embedded.

Other studies have reported the manufacturing of PEEK/ 45S5 coatings on metallic substrates using the electrophoretic deposition technique (Ref 13, 18). However, the development of PEEK/45S5 coatings on a PEEK substrate has not been studied to date. This blend of PEEK and $45 \mathrm{~S} 5$ will be the first time that a bioactive glass has been deposited by the CGS technique.

The aim of the present work was to develop functional materials by depositing a composite PEEK/45S5 coating on PEEK samples to improve their response when implanted in the body. During the present investigation, the development of the abovementioned coatings by the CGS technique was studied, analyzing in particular the effects of the glass content. A study of the wear behavior was also carried out. The overall objective was to create a coating that can maintain appropriate mechanical properties while ensuring bioactivity and a good bone cell response.

\section{Materials and Methods}

\section{Powders and Substrates}

To provide the bioactive capacity, a commercial $45 \mathrm{~S} 5$ bioactive glass powder (Denfotex Research, United Kingdom) was selected, which was produced by the traditional melt-quenching route. A commercial PEEK powder (Victrex, United Kingdom) was used as the polymeric matrix of the coating. The coatings were deposited onto flat PEEK substrates measuring $50 \mathrm{~mm} \times 100 \mathrm{~mm} \times 5 \mathrm{~mm}$ (Ensinger, Spain) for the deposition efficiency studies.

PEEK disks with a $25 \mathrm{~mm}$ diameter, cut from a PEEK bar (Vestakeep, Spain), were used to determine the wear behavior of the coatings and to evaluate the cross section of the coatings.

\section{Powder Characterization}

The morphology of the powders was determined using a scanning electron microscope (SEM) equipped with a backscattered electron detector (Phenom ProX, PhenomWorld BV, Eindhoven, the Netherlands). Before the microscopy studies, all the samples were coated by a gold layer to make them conductive using a SEM coating unit (E-5000, Polaron, Watford, England).

A laser diffraction particle size analyzer (LS 13320, Beckman Coulter, California, USA) was used to measure the granulometry of the powders. Commercial PEEK and $45 \mathrm{~S} 5$ powders were sieved to obtain two powder fractions of each material using a $63 \mu \mathrm{m}$ and a $40 \mu \mathrm{m}$ mesh sieve (Retsch, Germany). In this way, it was possible to assess the effect of the granulometry on the deposition efficiency (DE) and the thickness of the coatings. Since powders of small particles on the micrometric scale (between 1 and 50 $\mu \mathrm{m})$ (Ref 39) are recommended for the CGS technique, the 
ranges selected were those between 40 and $63 \mu \mathrm{m}$, called the "coarse range," and those below $40 \mu \mathrm{m}$, called the "fine range."

The tapped density $\left(\rho_{t}\right)$ of the different powders was measured using a graduated cylinder. The powder was tapped regularly to settle the powder inside the cylinder. The filling and tapping process was repeated until the volume of the powder remained fixed at $5 \mathrm{ml}$.

\section{Coating Deposition}

For the coating deposition, the low-pressure cold gas spray (LPCGS) equipment (Dymet 423, Dycomet Europe, Akkrum, the Netherlands) was used with air as the propellant gas. The blends were deposited onto PEEK substrates previously grit blasted (Formula 1400, Guyson International, Skipton, England) with corundum G24 (grit size 800 $\mu \mathrm{m})$ at a pressure of $0.5 \mathrm{MPa}$. Afterward, the substrates were cleaned with ethanol. The surface roughness after the grit blasting process was $\mathrm{Ra}=4.9 \pm 0.4 \mu \mathrm{m}$ and $\mathrm{Rz}=27.3$ $\pm 2.8 \mu \mathrm{m}$. The spraying parameters are listed in Table 1 .

In this study, coatings with two different thickness were produced by varying the traverse gun speed. The thick coatings, which allow a better observation, were sprayed using low traverse gun speed $(80 \mathrm{~mm} / \mathrm{s})$ and were used for characterizing the materials deposition, microstructure and distribution of the elements. Using a high traverse gun speed $(240 \mathrm{~mm} / \mathrm{s})$, thin coatings were obtained. These coatings, with a suitable thickness for the final application, were used to study the wear and hardness of the coatings.

The LPCGS is a thermal spray technique that involves relatively low temperatures. The equipment used allowed us to work with gas temperatures ranging from room temperature to $500{ }^{\circ} \mathrm{C}$. This enabled us to spray polymers without decomposing them. The glass transition temperature of PEEK starts at $143{ }^{\circ} \mathrm{C}$, with melting achieved at $343{ }^{\circ} \mathrm{C}$ and the decomposition starting at $575{ }^{\circ} \mathrm{C}(\operatorname{Ref} 40)$. Moreover, the amorphous structure of the bioactive glass is not affected at the studied temperatures $\left(300-350{ }^{\circ} \mathrm{C}\right)$. The

Table 1 Cold gas spraying parameters

\begin{tabular}{ll}
\hline \multicolumn{1}{c}{ Spraying parameters } & \\
\hline Pressure, $\mathrm{MPa}$ & $0.5-0.6$ \\
Gas temperature, ${ }^{\circ} \mathrm{C}$ & $300-350$ \\
Spray distance, $\mathrm{mm}$ & 10 \\
Layers & 1 \\
Gun traverse speed, $\mathrm{mm} / \mathrm{s}$ & $80-240$ \\
Incremental steps, $\mathrm{mm}$ & 0.75 \\
Nozzle & $\mathrm{CK}-20$ \\
Powder feed rate, $\mathrm{g} / \mathrm{min}$ & 15 \\
\hline
\end{tabular}

glass transition temperature of the $45 \mathrm{~S} 5$ bioactive glass starts at $550{ }^{\circ} \mathrm{C}$ and melting occurs at $1070{ }^{\circ} \mathrm{C}(\operatorname{Ref} 41)$.

The DE is the ratio in percentage of the mass of the material deposited on the specimen to the mass of the sprayed material.

$\mathrm{DE}(\%)=\frac{\Delta m_{\text {specimen }}}{\Delta m_{\text {sprayedmaterial }}} \times 100$

As mentioned before, the granulometry of the powders can affect the DE and the thickness of the coatings. A preliminary study was conducted to choose the optimal size distribution of the powders to develop subsequent tests. Hence, three blends of fine and coarse powders were sprayed, with the amount of glass powder kept at $10 \%$ in volume in all the cases. These blends corresponded to: PEEK/45S5 (fine/fine), using the fine range of both powders; PEEK/45S5 (coarse/fine), using the coarse and fine range of PEEK and 45S5, respectively; and PEEK/45S5 (coarse/coarse), using the coarse range of both powders. In addition, PEEK powders corresponding to the fine and coarse range were also sprayed to determine the DE of the polymeric material with a different particle size distribution.

After the preliminary study, the effect of glass content on the blends was evaluated using the selected granulometry of the powders. For this purpose, the blends of PEEK and the bioactive glass were prepared by manually mixing: $0,10,25,35$ and 50 volume percentages of 45S5.

\section{Coating Characterization}

The thickness of the coating was measured from the crosssectional images of each coating using an optical microscope (DMI 5000 M, Leica, Wetzlar, Germany). The calculation of the thickness involved measuring the width of the cross section at eight points distributed along the length of each microsection and calculating the arithmetic mean of the measurements. For each coating, five cross-sectional images were taken at a magnification of 50x.

The cross sections of the coatings were prepared by cold mounting resin and grinding them with silicon carbide abrasive papers up to P4000 (grit size $5 \mu \mathrm{m}$ ). Finally, the samples were polished with $1 \mu \mathrm{m}$ diamond solution.

To confirm the influence of the glass powder on the thickness of the samples, coatings with significantly different thicknesses were analyzed. Depending on the gun traverse speed used, different thicknesses were obtained. Thicknesses of approximately 900-700 $\mu \mathrm{m}$ were obtained at a traverse speed of $80 \mathrm{~mm} / \mathrm{s}$, whereas thicknesses of 300-200 $\mu \mathrm{m}$ were obtained when applying a traverse speed of $240 \mathrm{~mm} / \mathrm{s}$.

To analyze the distribution of the elements of the blend in the cross section, an elemental mapping was performed 
on the gold-covered cross sections. The main element of the glass, silicon, was chosen to identify the presence of 45S5 in the coating. An SEM (JSM-5310, JEOL, Tokyo, Japan) equipment with energy-dispersive $\mathrm{x}$-ray spectroscopy (EDS) was used for this analysis.

The glass content within the coating was analyzed on large areas of the coatings sprayed with a lower gun traverse speed that allowed a better observation of the particle distribution.

Image analysis of the micrographs was done to quantify the area percentage of glass material by means of ImageJ program. The area percentage was measured by an average of 5 images for each coating, taken at a magnification of 200x. It should be noted that the glass quantity on the coatings calculated corresponds to an area percentage and cannot be compared with the volumetric percentages of the blends.

\section{Tribological Behavior of the Coatings}

A ball-on-disk test under dry conditions was developed to characterize the wear and friction behavior of the coatings. Four tests were performed for each coating, applying a load of $5 \mathrm{~N}$ at a constant velocity of $133 \mathrm{rpm}$ for a total sliding distance of $1000 \mathrm{~m}$. Alumina balls with a diameter of $9 \mathrm{~mm}$ were used and the track radius developed on the samples was $13 \mathrm{~mm}$. The surfaces were prepared to obtain an Ra value under $0.8 \mu \mathrm{m}$ to meet the specifications of the ASTMG99-95 (Ref 42). All the tests were performed at room temperature with a relative humidity of about $30 \%$.

After the tests, the wear track of each sample was analyzed at four different points employing a confocal microscope (PLu 2300, Sensofar, Barcelona, Spain) to calculate the volume of lost material due to wear. For this evaluation, the track cross-sectional area was multiplied by the track length to obtain the wear volume.

In addition, the wear scars and the alumina balls were examined by SEM to analyze the effects of the wear mechanisms involved in the process.

Finally, hardness was measured on polished cross sections, using a micro Vickers hardness tester (MXT-01, Matsuzawa Seiki, Tokyo, Japan). For each coating, ten indentations were done along the cross section under a load of $50 \mathrm{gf}$.

\section{Results and Discussion}

\section{Powder Characterization}

The morphology of the powders can be seen in Fig. 1. The 45S5 powder shows an irregular morphology with angularshaped particles, as expected due to the route of

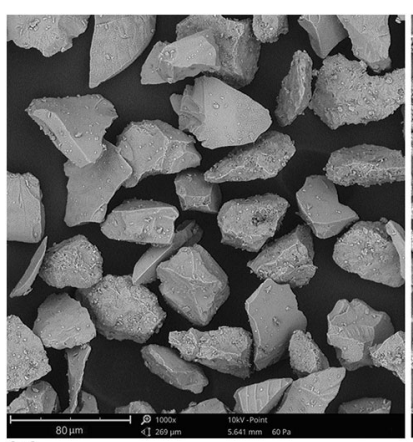

(a)

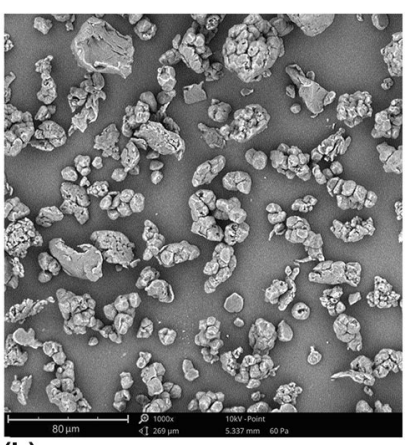

(b)
Fig. 1 SEM micrographs of the free surface of bioactive glass (a) and PEEK (b) powders

fabrication. The free surface of the PEEK powder presents a spherical and porous morphology of the agglomerated powder, with agglomerated particles measuring between 5 and $40 \mu \mathrm{m}$.

The characteristic values of the size distribution of the powders and their density are listed in Table 2 . The glass particles were larger than the PEEK ones, as can be seen when comparing the same sieved ranges. This difference can be explained by: firstly, the size of the particles of the initial powder, where the PEEK powder had a larger quantity of fine particles; secondly, the angular morphology of the glass powder that allowed the narrow and elongated particles to pass through the sieve on their narrowest side; and finally, the higher density of the glass powders that facilitated the passage of the particles through the sieve.

\section{Coating Deposition}

A preliminary study was carried out to determine the most suitable granulometry of the powders to produce the coatings. Taking into account the DE results of the PEEK powders (presented in Fig. 2), a higher efficiency was obtained when the fine range was used, with an increase of almost $10 \%$ of the DE compared to that obtained with the coarse range. For the blended powders, a higher DE was achieved when the PEEK/45S5 (fine/fine) blend was used. These results are in agreement with those of other studies showing that smaller polymeric particles reach higher values of DE with the CGS technique, which might be associated with a greater impact velocity (Ref 43). Furthermore, the lowest DE value was obtained with the PEEK/45S5 (coarse/coarse) blend.

Based on the results of this initial study, coatings were produced with the fine range of each material.

The influence of the glass content on the DE was analyzed using the PEEK/45S5 (fine/fine) blend. The results are presented in Fig. 3, which shows a clear tendency of the 
Table 2 Particle size distribution in volume and tapped density of the 45S5 and PEEK powders

\begin{tabular}{lccccc}
\hline & Mean, $\mu \mathrm{m}$ & $\mathrm{d}_{10}, \mu \mathrm{m}$ & $\mathrm{d}_{50}, \mu \mathrm{m}$ & $\mathrm{d}_{90}, \mu \mathrm{m}$ & $\rho_{t}, \mathrm{~g} / \mathrm{cm}^{3}$ \\
\hline PEEK - coarse range & 48.6 & 19.8 & 49.4 & 73.2 & 0.48 \\
PEEK - fine range & 22.5 & 10.2 & 21.2 & 37.6 & 0.42 \\
45S5 - coarse range & 56.5 & 20.6 & 57.9 & 84.9 & 1.38 \\
45S5 - fine range & 40.5 & 28.1 & 41.1 & 53.2 & 1.33 \\
\hline
\end{tabular}

Fig. 2 Deposition efficiency of blends with 90 vol.\% of PEEK and 10 vol. $\%$ of $45 \mathrm{~S} 5$ in the feedstock and different granulometry
Fig. 3 Deposition efficiency of mixtures PEEK/45S5 with different volume ratio in the feedstock
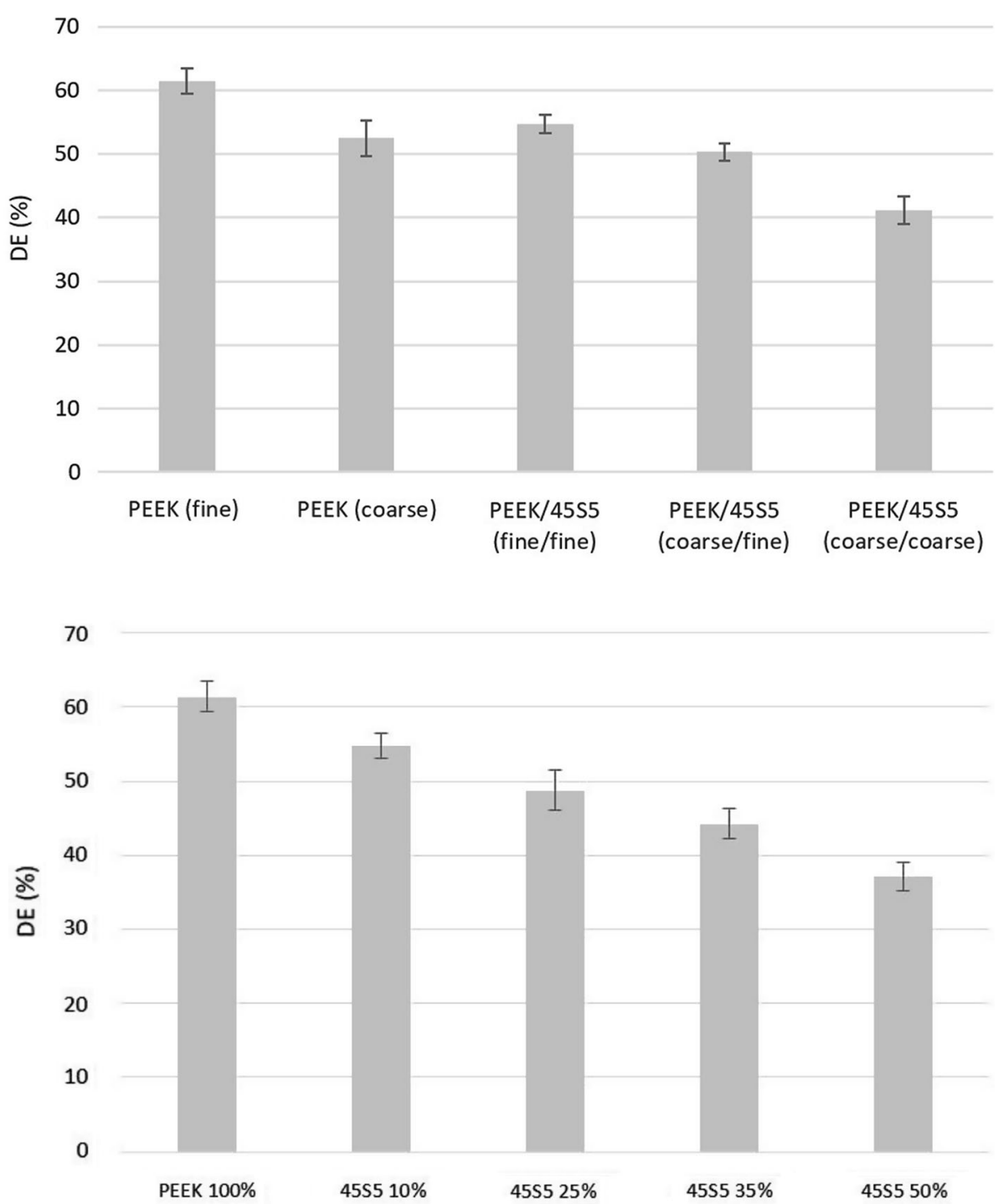

efficiencies decreasing with an increasing glass content in the feedstock. This effect can be attributed to the difficulty of depositing glass particles, which are brittle, with this technique. It has been widely demonstrated that in the CGS technique, plastic deformation of the particle that is impinging onto the substrate surface is required for particle adhesion. However, in this specific case (in polymers), thermal softening of the powder and proper substrate roughness play a major role in the adhesion to the substrate.
Considering the differences in the physical properties of the two feedstock materials, it can be assumed that it is easier for the polymers to reach deformation by thermal softening. Glass particles are more difficult to deform without melting and they impinge onto the substrate in a brittle state when sprayed. Glass particles are not deformed during the process and are embedded in a polymer matrix composed of the PEEK particles (Fig. 4). In addition, it is assumed that in blends with a lower PEEK content, the glass particles find fewer areas to adhere to and the impact 
Fig. 4 Cross-sectional SEM images: (a) 45S5 10\%, (b) 45S5 $25 \%$, (c) $45 \mathrm{~S} 535 \%$ and

(d) $45 \mathrm{~S} 550 \%$

Fig. 5 Coating thickness of PEEK/45S5 blends sprayed at low and high traverse speed
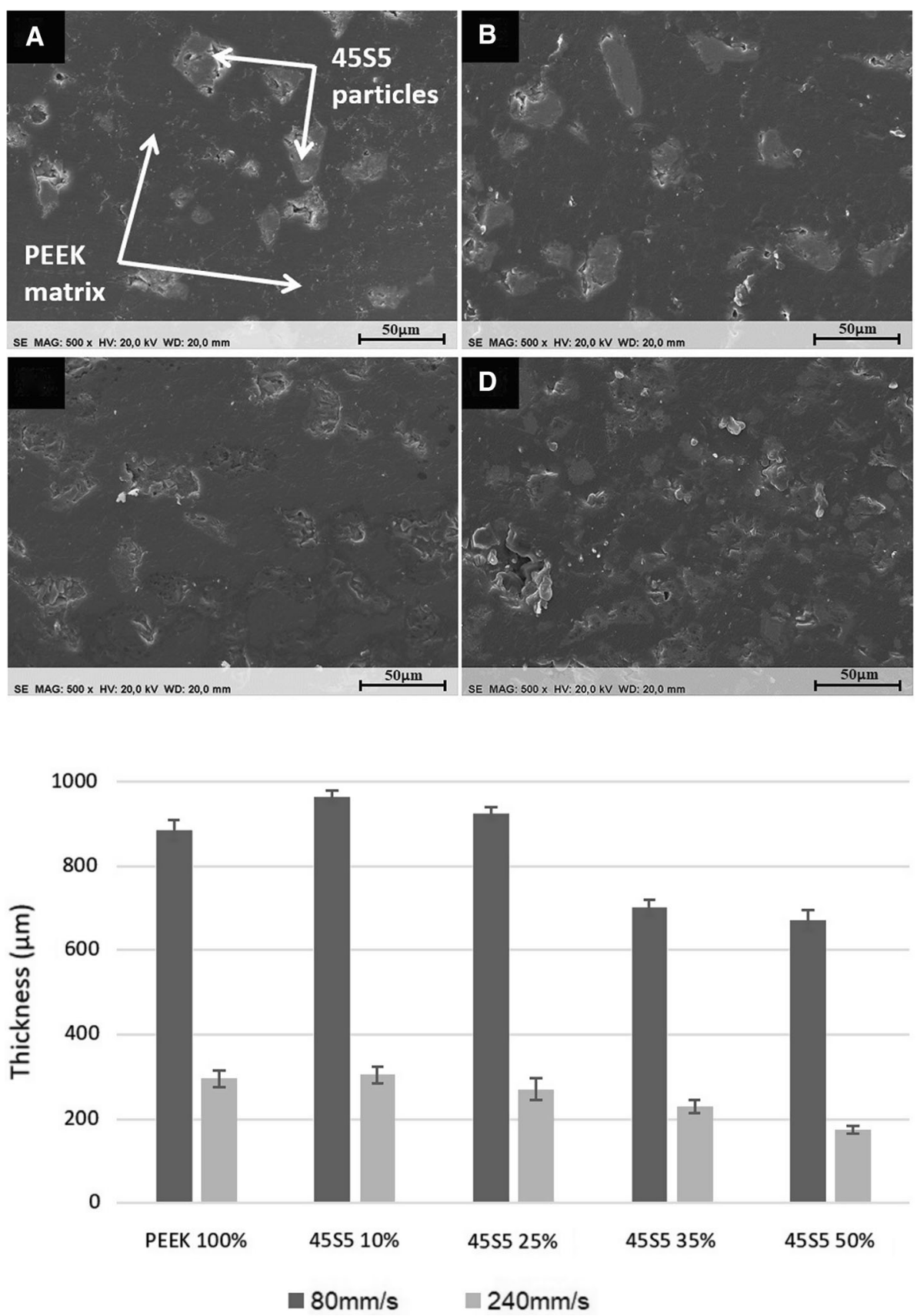

between the glass particles results in abrasive behavior. Therefore, the PEEK coating without glass showed the highest efficiency value of $61 \%$, with the DE gradually decreasing with the increasing presence of glass.

\section{Coating Characterization}

The effect of the glass content on the thickness of the coatings was determined by visual inspection of the cross sections of the coatings. This analysis was carried out on coatings obtained with different gun traverse speeds (80 $\mathrm{mm} / \mathrm{s}$ and $240 \mathrm{~mm} / \mathrm{s}$ ). The results are displayed in Fig. 5.
A slight increase in thickness was observed when the blend with 10 vol.\% of glass was used for both, the low and high speed, while the DE decreased slightly, as can be seen in Fig. 3 (low speed). This difference in tendency could be explained because the glass particles embedded into the coating are larger than the PEEK particles and did not deform during the spraying process. This could have caused the slight increase in the thickness of the coating produced with 10 vol.\% of glass.

The blends with glass content starting from 35 vol.\% resulted in a gradual decrease in the thickness, showing the same tendency as the DE. In the coatings with more glass, 
Fig. 6 EDS maps showing the distribution of silicon (representing glass) in the cross section: (a) 45S5 10\%, (b) 45S5 $25 \%$, (c) $45 \mathrm{~S} 535 \%$ and (d) $45 \mathrm{~S} 550 \%$
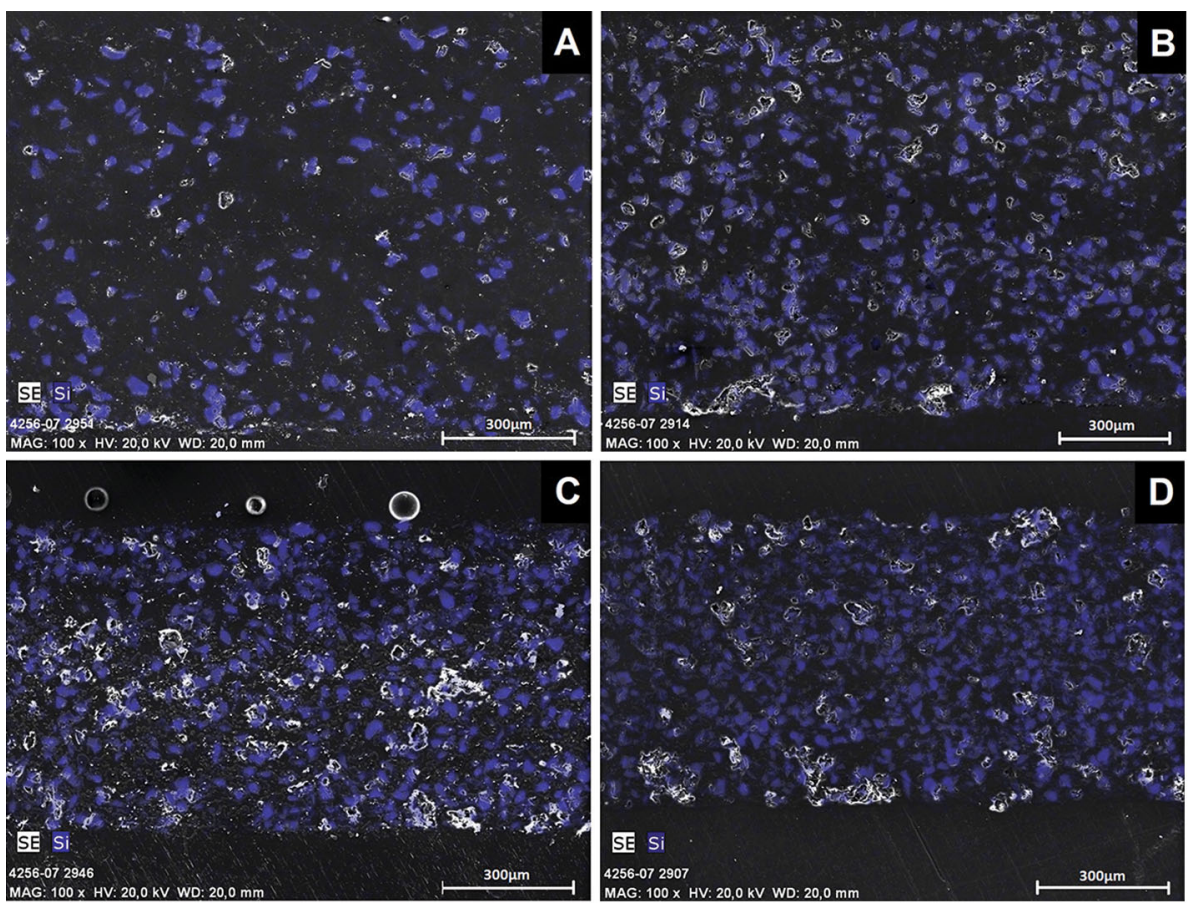

Table 3 Properties of the coatings obtained using PEEK/45S5 (fine/fine) blends

\begin{tabular}{lcccc}
\hline & $\begin{array}{c}\text { Glass quantity on coating, area } \\
\%\end{array}$ & $\begin{array}{c}\text { Coefficient of friction, } \\
\mu\end{array}$ & $\begin{array}{c}\text { Volume of lost material, } \\
\mathrm{mm}^{3}\end{array}$ & $\begin{array}{c}\text { Volume loss respect pure PEEK coating, } \\
\%\end{array}$ \\
\hline PEEK & $\ldots$ & $0.51 \pm 0.04$ & $0.790 \pm 0.236$ & $\ldots$ \\
$100 \%$ & & & \\
$45 \mathrm{~S} 510 \%$ & $6.9 \pm 0.1$ & $0.50 \pm 0.02$ & $0.181 \pm 0.018$ & 23 \\
$45 \mathrm{~S} 525 \%$ & $14.2 \pm 0.2$ & $0.40 \pm 0.03$ & $0.226 \pm 0.080$ & 29 \\
$45 \mathrm{~S} 535 \%$ & $27.9 \pm 1.1$ & $0.41 \pm 0.02$ & $0.200 \pm 0.070$ & 25 \\
$45 \mathrm{~S} 55 \%$ & $32.6 \pm 1.9$ & $0.37 \pm 0.04$ & $0.147 \pm 0.033$ & 19 \\
\hline
\end{tabular}

it is expected that the glass particles find fewer areas rich in PEEK particles to help in their adhesion when they reach the surface, resulting in thinner coatings.

In particular, the 25 vol. $\%$ coatings showed an intermediate result. The thickness of the coating sprayed at low traverse speed was higher than the PEEK $100 \%$ coating while the DE decreased. On the contrary, when this blend was sprayed at high traverse speed, the thickness of the coating decreased respect the pure PEEK coating, as well as the DE. This result could be explained because in the thicker coating, where more material is forming the coating, the effect of the size of the glass particles has a greater relevance.

The results corroborated that the presence of PEEK in the blend allows the deposition of the glass, which by itself cannot build up a coating.
The thickness of the pure PEEK coatings was exactly three times lower when the speed was increased by up to three times (Fig. 5). This indicated that PEEK particles can adhere to the substrate and to other particles with the same ease. On the contrary, in coatings containing glass, the thickness was reduced by more than 3 times when the speed was increased by up to three times. This may be due to the poor adhesion of the glass directly to the substrate.

For the coatings to be bioactive, it is important that the glass particles are well distributed throughout the coating, especially at its surface. For this purpose, the glass content was analyzed on the coatings sprayed with a lower gun traverse speed that allowed a better observation of the particle distribution. However, to validate this analysis, it was verified (analyzing one of the coatings sprayed at $240 \mathrm{~mm} / \mathrm{s}$ ) that the glass concentration in the coating is not affected by the gun traverse speed. 

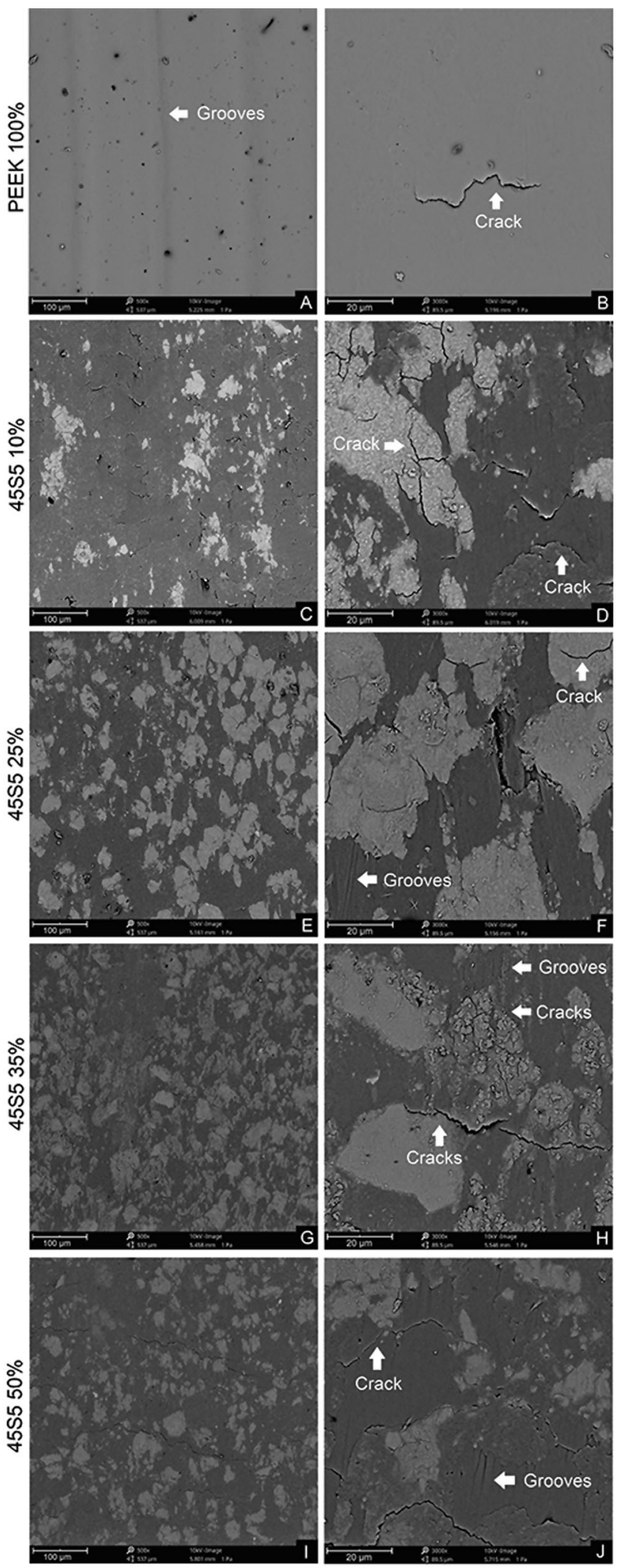

Fig. 7 SEM images of the wear track at low and high magnifications

A mapping of silicon, corresponding to the main element of the 45S5 glass, is shown in Fig. 6, and the results of area percentage, from the image analysis, are displayed in Table 3. The low standard deviation verifies the homogeneity of the distribution of the glass particles throughout the coating. In addition, it has been seen that the polymer matrix allows the deposition of a large amount of glass in the coating, producing a coating with up to an area of $32 \%$ of glass when the blend with 50 vol. $\%$ of glass was used. Moreover, as can be seen in Fig. 5, glass particles were also found on the surface of the coating, thus indicating its potential bioactive capacity.

\section{Wear Friction Study}

The mean value of the wear coefficient calculated in the last $200 \mathrm{~m}$ is shown in Table 3. Furthermore, the volume of lost material was determined by confocal microscopy. The test was carried out on the coatings obtained by spraying blends with different glass contents at $240 \mathrm{~mm} / \mathrm{s}$, which provided sufficiently thick coatings for the test.

When analyzing the coatings without any glass content, some holes could be observed, which corresponded to PEEK particles that had been pulled out from the coating matrix (Fig. 7a, b). Furthermore, clear plowing was observed, where PEEK particles from the coating had been pushed and displaced to form ridges adjacent to the grooves found in the sliding track (Fig. 7a).

It is assumed that some of the PEEK particles that had detached during the test were deposited again onto the track, while others adhered to the alumina ball and some appeared as debris on the surface of the coatings after the test.

A different mechanism was observed when glass particles were present in the coatings. There were several cracks on the glass particles (clear particles in Fig. $7 d, f, h, j$ ). It seems that the detached glass fragments caused parallel grooves on the sliding track (Fig. $7 \mathrm{~d}, \mathrm{f}, \mathrm{h}, \mathrm{j}$ ) before being re-encrusted onto the PEEK-rich areas of the track. This was assumed because no holes related to the PEEK particles were observed in the sliding track, while small glass particles were seen on the track that were smaller in size than the feedstock glass particles.

From the results obtained, it is assumed that a path with a progressively higher glass content was generated during the test. It was noticed that glass particles prevented the detachment of the polymer particles, resulting in a significant decrease in wear that was reflected by a remarkable reduction in the volume of lost material and a decrease in the coefficient of friction.

In the samples with a low glass content (10 vol.\% of 45S5), the volume of lost material was significantly reduced when compared to the coatings with no glass (from 0.790 to $0.181 \mathrm{~mm}^{3}$ ). However, the coefficient of friction decreased only slightly (from 0.51 to 0.50 ). 
Fig. 8 Alumina balls after the ball-on-disk test
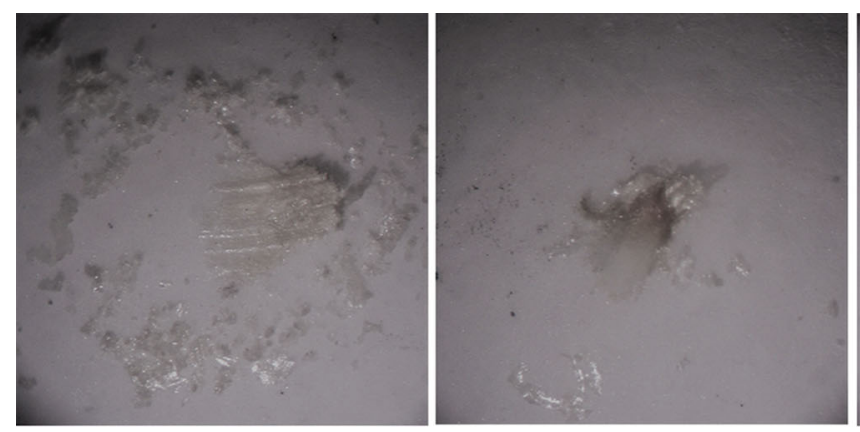

PEEK $100 \%$

$45 S 510 \%$

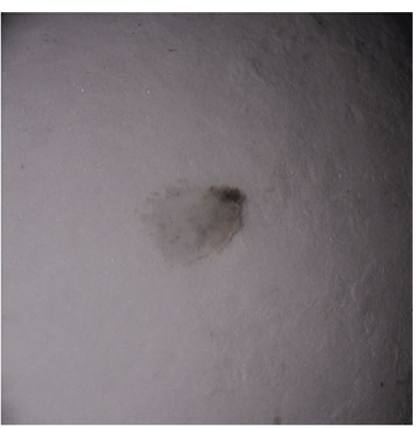

$45 S 525 \%$

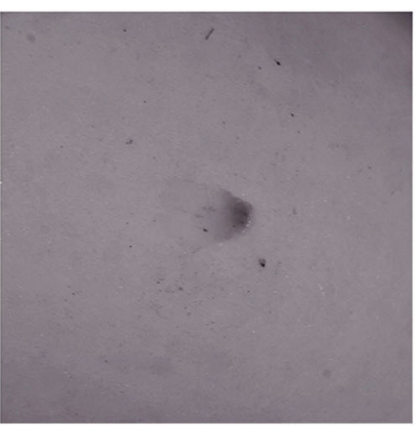

$45 \mathrm{~S} 535 \%$

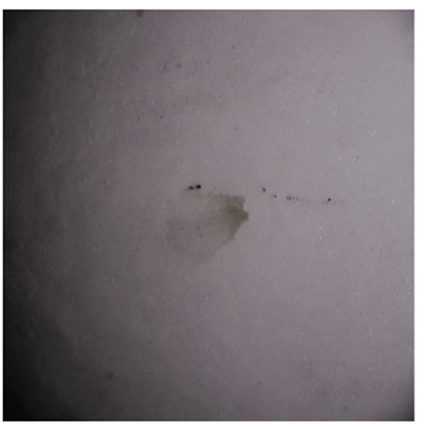

$45 S 550 \%$

Fig. 9 Vickers hardness values of PEEK/45S5 composite coatings.

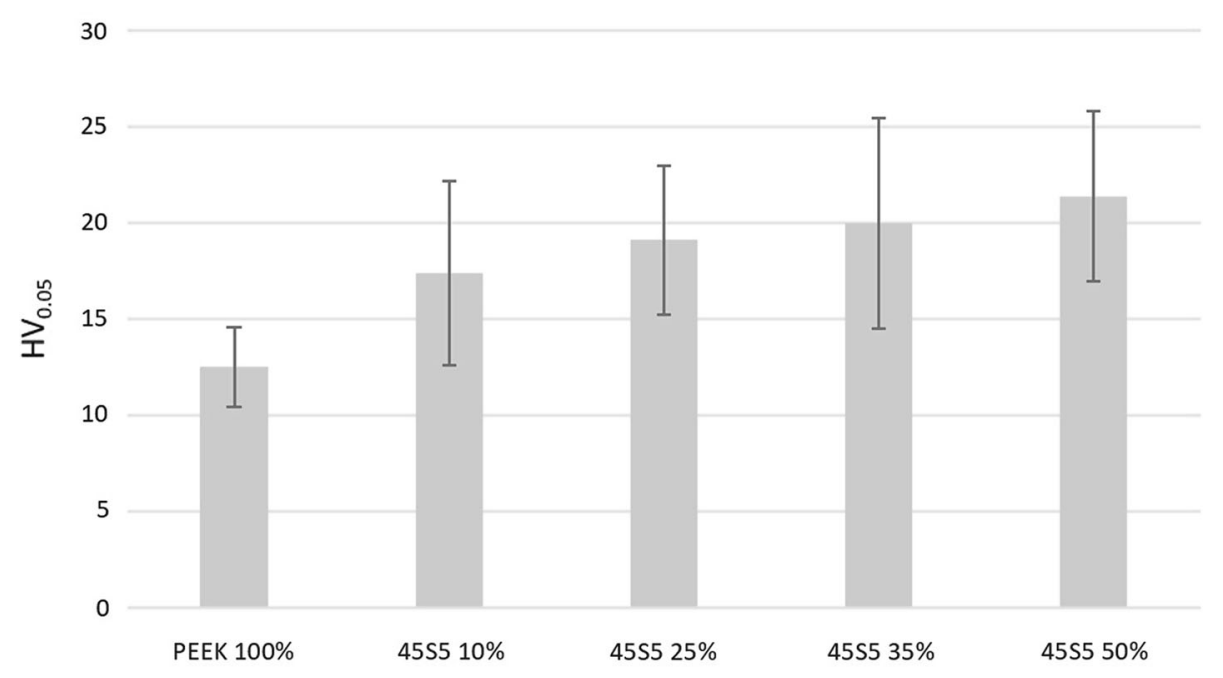

On the surfaces of these coatings, debris related to the PEEK particles appeared after the test and PEEK particles also adhered to the alumina balls, as can be seen in Fig. 8. Both events occurred to a lesser degree in the coatings with glass. The amount of glass in the coatings with $10 \mathrm{vol} \%$ of 45S5 was not enough to provide a clear protection against wear.

Finally, in the coatings containing 25 vol. $\%$ or more of glass, no debris was observed on the surface after the test and fewer PEEK particles adhered to the alumina balls (Fig. 8). The fragments of glass particles were re-encrusted onto the sliding track, producing a path with a high amount of glass that meant better resistance against wear and generating lower coefficient of friction values for these coatings, particularly those containing 50 vol.\% of $45 \mathrm{~S} 5$.

The hardness results obtained can be seen in Fig. 9. Coatings containing glass show higher values of hardness when compared to pure PEEK coatings. The glass particles provide less deformability to the composite coating, and for this reason, the hardness increases slightly with the presence of glass.

The higher hardness of coatings containing glass causes the wear resistance increase and the reduction in the volume of lost material evaluated in the wear friction study. 


\section{Conclusions}

This study demonstrated that the LPCGS technology can easily produce 45S5/PEEK bioactive coatings with improved wear resistance.

The use of PEEK in the blend material facilitated the deposition of bioactive glass particles by the CGS technique. In this way, a bioactive component could be incorporated into the coatings. Further studies should be conducted to validate the bioactivity of the developed composite coatings.

The highest DE values were obtained when mixtures of fine particles were used. Decreases in the DE and the coating thickness were observed with an increasing glass content in the blend. This was probably due to the glass particles not being deformed during the process, but only being embedded into a polymer matrix composed of PEEK particles. In addition, the cross sections revealed that the glass particles were homogeneously distributed throughout the coatings.

The high degree of wear caused on the pure PEEK coatings can be explained by the plastic deformation of the PEEK particles. The presence of glass in the coatings increased wear resistance, as reflected by a decrease in the coefficient of friction and a reduction in the volume of lost material (more than $70 \%$ when compared to the pure PEEK coatings). In this case, glass particles prevented the polymeric particles from detaching. The coating containing 50 vol.\% of $45 \mathrm{~S} 5$ showed the highest wear resistance and hardness.

\section{References}

1. S. Kurtz, K. Ong, E. Lau, F. Mowat and M. Halpern, Projections of Primary and Revision Hip and Knee Arthroplasty in the United States from 2005 to 2030, J. Bone Jt. Surg. Ser. A, 2007, 89(4), p 780-785.

2. B.D. Ratner, A.S. Hoffman, F.J. Schoen and J. Lemons, Biomaterials Science: A Multidisciplinary Endeavor, Biomaterials Science, 2nd ed., B.D. Ratner, A.S. Hoffman, F.J. Schoen, J. Lemons Ed., Academic Press, New York, 2004, p 1-20

3. N. Patel and P. Gohil, A Review on Biomaterials: Scope, Applications \& Human Anatomy Significance, Int. J. Emerg. Technol. Adv. Eng., 2012, 2(4), p 91-101.

4. B. Dhandayuthapani and D.K. Sakthi, Biomaterials for Biomedical Applications, Biomedical Applications of Polymeric Materials and Composites. R. Francis, D.K. Sakthi Ed., Wiley-VCH Verlag, Hoboken, 2016, p 1-20

5. M. Saini, Implant Biomaterials: A Comprehensive Review, World J. Clin. Cases, 2015, 3(1), p 52-57.

6. W. Jin and P.K. Chu, Orthopedic Implants, Encyclopedia of Biomedical Engineering. R. Narayan Ed., Elsevier, Amsterdam, 2019, p 425-439
7. S.M. Kurtz and J.N. Devine, PEEK Biomaterials in Trauma, Orthopedic, and Spinal Implants, Biomaterials, 2007, 28(32), p 4845-4869.

8. D. Almasi, N. Iqbal, M. Sadeghi, I. Sudin, M.R. Abdul Kadir and T. Kamarul, Preparation Methods for Improving PEEK's Bioactivity for Orthopedic and Dental Application: A Review, Int. J. Biomater., 2016, 2016, p 1-12.

9. M.A. Ur Rehman, F.E. Bastan, A. Nawaz, Q. Nawaz and A. Wadood, Electrophoretic Deposition of PEEK/Bioactive Glass Composite Coatings on Stainless Steel for Orthopedic Applications: An Optimization for in Vitro Bioactivity and Adhesion Strength, Int. J. Adv. Manuf. Technol., 2020, 108(5-6), p 1849-1862.

10. A. Nawaz, S. Bano, M. Yasir, A. Wadood and M.A. Ur Rehman, $\mathrm{Ag}$ and Mn-Doped Mesoporous Bioactive Glass Nanoparticles Incorporated into the Chitosan/Gelatin Coatings Deposited on PEEK/Bioactive Glass Layers for Favorable Osteogenic Differentiation and Antibacterial Activity, Mater. Adv., 2020, 1(5), p 1273-1284.

11. S.W. Ha, M. Kirch, F. Birchler, K.L. Eckert, J. Mayer, E. Wintermantel, C. Sittig, I. Pfund-Klingenfuss, M. Textor, N.D. Spencer, M. Guecheva and H. Vonmont, Surface Activation of Polyetheretherketone (PEEK) and Formation of Calcium Phosphate Coatings by Precipitation, J. Mater. Sci. Mater. Med., 1997, 8(11), p 683-690.

12. J.P. Fan, C.P. Tsui, C.Y. Tang and C.L. Chow, Influence of Interphase Layer on the Overall Elasto-Plastic Behaviors of HA/ PEEK Biocomposite, Biomaterials, 2004, 25(23), p 5363-5373.

13. M.A. Ur Rehman, F.E. Bastan, Q. Nawaz, W.H. Goldmann, M. Maqbool, S. Virtanen and A.R. Boccaccini, Electrophoretic Deposition of Lawsone Loaded Bioactive Glass (BG)/Chitosan Composite on Polyetheretherketone (PEEK)/BG Layers as Antibacterial and Bioactive Coating, J. Biomed. Mater. Res. Part A, 2018, 106(12), p 3111-3122.

14. Y. Torres, C. Romero, Q. Chen, G. Pérez, J.A. Rodríguez-Ortiz, J.J. Pavón, L. Álvarez, C. Arévalo and A.R. Boccaccini, Electrophoretic Deposition of PEEK/45S5 Bioactive Glass Coating on Porous Titanium Substrate: Influence of Processing Conditions and Porosity Parameters, Key Engineering Materials. T. Ebel, F. Pyczak Ed., Trans Tech Publications, Zurich, 2016, p 343-350

15. M. Miola, E. Verné, A. Piredda, S. Seuss, S. Cabanas-Polo and A.R. Boccaccini, Development and Characterization of PEEK/ $\mathrm{B}_{2} \mathrm{O}_{3}$-Doped 45S5 Bioactive Glass Composite Coatings Obtained by Electrophoretic Deposition, Key Engineering Materials, Vol 654, A.R. Boccaccini, J.H. Dickerson, B. Ferrari, O. Van der Biest, T. Uchikoshi Ed., Trans Tech Publications, Zurich, 2015, p $165-169$

16. S. Yu, K. Prakash, R. Kumar and P. Cheang, In Vitro Apatite Formation and Its Growth Kinetics on Hydroxyapatite/ Polyetheretherketone Biocomposites, Biomaterials, 2005, 26, p 2343-2352.

17. W. Hong, F. Guo, J. Chen, X. Wang, X. Zhao and P. Xiao, Bioactive Glass-Chitosan Composite Coatings on PEEK: Effects of Surface Wettability and Roughness on the Interfacial Fracture Resistance and in Vitro Cell Response, Appl. Surf. Sci., 2018, 440, p 514-523.

18. S. Seuss, M. Heinloth and A.R. Boccaccini, Surface \& Coatings Technology Development of Bioactive Composite Coatings Based on Combination of PEEK, Bioactive Glass and Ag Nanoparticles with Antibacterial Properties, Surf. Coat. Technol., 2016, 301, p 100-105.

19. L.L. Hench and J.R. Jones, Bioactive Glasses: Frontiers and Challenges, Front. Bioeng. Biotechnol., 2015, 3, p 194.

20. G. Kaur, V. Kumar, F. Baino, J.C. Mauro, G. Pickrell, I. Evans and O. Bretcanu, Mechanical Properties of Bioactive Glasses, Ceramics, Glass-Ceramics and Composites: State-of-the-Art 
Review and Future Challenges, Mater. Sci. Eng. C, 2019, 104, p 109895.

21. A. Hoppe, N.S. Güldal and A.R. Boccaccini, A Review of the Biological Response to Ionic Dissolution Products from Bioactive Glasses and Glass-Ceramics, Biomaterials, 2011, 32(11), p 2757-2774.

22. D.S. Brauer, Bioactive Glasses - Structure and Properties, Angew. Chem. Int. Ed., 2015, 54(14), p 4160-4181.

23. J.R. Jones, Review of Bioactive Glass: From Hench to Hybrids, Acta Biomater., 2013, 9(1), p 4457-4486.

24. S. Lopez-Esteban, E. Saiz, S. Fujino, T. Oku, K. Suganuma and A.P. Tomsia, Bioactive Glass Coatings for Orthopedic Metallic Implants, J. Eur. Ceram. Soc., 2003, 23(15), p 2921-2930.

25. N.C. Lindfors, I. Koski, J.T. Heikkilä, K. Mattila and A.J. Aho, A Prospective Randomized 14-Year Follow-up Study of Bioactive Glass and Autogenous Bone as Bone Graft Substitutes in Benign Bone Tumors, J. Biomed. Mater. Res. Part B Appl. Biomater., 2010, 94B(1), p 157-164.

26. N.C. Lindfors, P. Hyvönen, M. Nyyssönen, M. Kirjavainen, J. Kankare, E. Gullichsen and J. Salo, Bioactive Glass S53P4 as Bone Graft Substitute in Treatment of Osteomyelitis, Bone, 2010, 47(2), p 212-218.

27. K. Pernaa, I. Koski, K. Mattila, E. Gullichsen, J. Heikkilä, A.J. Aho and N.C. Lindfors, Bioactive Glass S53P4 and Autograft Bone in Treatment of Depressed Tibial Plateau Fractures: A Prospective Randomized 11-Year Follow-Up, J. Long. Term. Eff. Med. Implants, 2011, 21(2), p 139-148.

28. T. Debnath, A. Chakraborty and T. Pal, A Clinical Study on the Efficacy of Hydroxyapatite-Bioactive Glass Composite Granules in the Management of Periodontal Bony Defects, J. Indian Soc. Periodontol., 2014, 18(5), p 593-600.

29. A.A. El-Rashidy, J.A. Roether, L. Harhaus, U. Kneser and A.R. Boccaccini, Regenerating Bone with Bioactive Glass Scaffolds: A Review of in Vivo Studies in Bone Defect Models, Acta Biomater., 2017, 62, p 1-28.

30. E. Irissou, J.G. Legoux, A.N. Ryabinin, B. Jodoin and C. Moreau, Review on Cold Spray Process and Technology: Part I-Intellectual Property, J. Therm. Spray Technol., 2008, 17(4), p 495-516.

31. A.M. Vilardell, N. Cinca, A. Concustell, S. Dosta, I.G. Cano and J.M. Guilemany, Cold Spray as an Emerging Technology for Biocompatible and Antibacterial Coatings: State of Art, J. Mater. Sci., 2015, 50(13), p 4441-4462.

32. V.K. Champagne, Introduction, The Cold Spray Materials Deposition Process. V.K. Champagne Ed., Elsevier, Amsterdam, 2007, p 1-7

33. R. Kromer, R.N. Raoelison, C. Langlade, Y. Xie, M.P. Planche, T. Sapanathan and S. Costil, Cold Gas Dynamic Spray
Technology: A Comprehensive Review of Processing Conditions for Various Technological Developments till to Date, Addit. Manuf., 2017, 19, p 134-159.

34. O. Rojas, M. Prudent, M.E. López, F. Vargas and H. Ageorges, Influence of Atmospheric Plasma Spraying Parameters on Porosity Formation in Coatings Manufactured from 45S5 Bioglass ${ }^{\circledR}$ Powder, J. Therm. Spray Technol., 2020, 29(1-2), p $185-198$

35. V.L. Calvo, M.V. Cabedo, E. Bannier, E.C. Recacha, A.R. Boccaccini, L.C. Arias and E.S. Vilches, 45S5 Bioactive Glass Coatings by Atmospheric Plasma Spraying Obtained from Feedstocks Prepared by Different Routes, J. Mater. Sci., 2014, 49(23), p 7933-7942.

36. B. Garrido, I.G. Cano and S. Dosta, Adhesion Improvement and in Vitro Characterisation of 45S5 Bioactive Glass Coatings Obtained by Atmospheric Plasma Spraying, Surf. Coatings Technol., 2021, 405, p 126560.

37. G. Bolelli, N. Stiegler, D. Bellucci, V. Cannillo, R. Gadow, A. Killinger, L. Lusvarghi and A. Sola, Deposition Mechanisms in High Velocity Suspension Spraying: Case Study for Two Bioactive Materials, Surf. Coat. Technol., 2012, 210, p 28-45.

38. N. Sanpo, M.L. Tan, P. Cheang and K.A. Khor, Antibacterial Property of Cold-Sprayed HA-Ag/PEEK Coating, J. Therm. Spray Technol., 2009, 18(1), p 10-15.

39. P. Vuoristo, Thermal Spray Coating Processes, Comprehensive Materials Processing. S. Hashmi Ed., Elsevier, Amsterdam, 2014, p 229-276

40. P. Patel, T.R. Hull, R.W. McCabe, D. Flath, J. Grasmeder and M. Percy, Mechanism of Thermal Decomposition of Poly(Ether Ether Ketone) (PEEK) from a Review of Decomposition Studies, Polym. Degrad. Stab., 2010, 95(5), p 709-718.

41. L. Lefebvre, J. Chevalier, L. Gremillard, R. Zenati, G. Thollet, D. Bernache-Assolant and A. Govin, Structural Transformations of Bioactive Glass 45S5 with Thermal Treatments, Acta Mater., 2007, 55(10), p 3305-3313.

42. Test Method for Wear Testing with a Pin-on-Disk Apparatus, G99-17. Annual Book of ASTM Standards, Part 17, ASTM, 2017, p 1-6.

43. Y. Xu and I.M. Hutchings, Cold Spray Deposition of Thermoplastic Powder, Surf. Coatings Technol., 2006, 201(6), p 3044-3050.

Publisher's Note Springer Nature remains neutral with regard to jurisdictional claims in published maps and institutional affiliations. 